\title{
13. On the Photochemical Addition Reaction of Methylmercaptane with Vinylacetate, Vinylchloride and Allylalcohol
}

\author{
By Toshio Hoshino, Kazuo Yamagishi, and Yuzaburo Ichikawa \\ Organic Chemical Division, Tokyo Institute of Technology, Tokyo \\ (Comm. by R. Majima, M.J.A., Feb. 12, 1953)
}

By the irradiation of super high pressure mercury lamp (SHLType M.H.L. -200) on the equivalent mixture of methylmercaptane and vinylacetate, vinylchloride or allylalcohol in the oxygen atmosphere with or without added mercuric methylmercaptide, $\beta$-methylmercapto-ethylacetate, $\beta$-chloroethylmethylsulfide and methionol as the additive products were obtained in yield $93-95 \%$. In this case the heat of reaction evolute vigorously and the main reaction is almost completed in 20 minutes. The same result was obtained in treating the same reaction in the nitrogen atmosphere instead of oxygen in the presence of mercuric methylmercaptide, which is insoluble in the reaction mixture and added in a fine powder. In this case mercuric methylmercaptide makes a green yellow complex, which immediately changes to grey fine powder with vigorous evolution of heat, just then the reaction is nearly completed.

The boiling point of the new compound $\beta$-methylmercapto-ethylacetate is $79-80^{\circ} / 21 \mathrm{~mm}$ and the melting point of the doublesalt of the compound with mercuric chloride $\left(\mathrm{CH}_{3} \mathrm{SCH}_{2} \mathrm{CH}_{2} \mathrm{OCOCH}_{3} \cdot \mathrm{HgCl}_{2}\right)$ is 94-95 ${ }^{\circ}$.

Synthetic methods of preparation for the methionol by the addition reaction of methylmercaptane with allylalcohol in the presence of mercuric methylmercaptide, oxygen or sunlight have been reported by Kaneko" ${ }^{1)}$. According to his report, the highest yield (93\%) was obtained by standing the reaction mixture for a month in the presence of mercuric methylmercaptide, oxygen and sunlight.

The authors wish to express their thanks to Mr. Saburo Fujii, who is the assistant of the department of physical chemistry of the Tokyo Institute of Technology, for the use of M.H.L. -200 and for his helpful suggestions.

1) Jour. Chem. Soc. Japan, 59, 1139 (1938). 